\title{
Negación pictórica en contextos inferenciales
}

\section{[Pictorial Negation In Inferential Contexts]}

\author{
MARIELA AGUILERA \\ Universidad Nacional de Córdoba \\ Instituto de Humanidades \\ Consejo Nacional de Investigaciones Científicas y Técnicas \\ maguilera@ffyh.unc.edu.ar
}

\begin{abstract}
Resumen: De acuerdo con Barceló, la posibilidad de la negación pictórica constituye una prueba a favor del externismo lógico porque no depende de encontrar elementos internos en las imágenes que expresan la negación. Propongo analizar la negación pictórica en contextos de razonamiento para mostrar cómo el contenido de una imagen se determina por relaciones lógicas externas. Para ello, propongo restringir el análisis del dominio completo de relaciones lógicas externas a contextos específicos de razonamiento. Lejos de rechazar la variante externista de Barceló, espero de esta forma poner a trabajar sus ideas.
\end{abstract}

Palabras clave: Razonamiento heterogéneo; externismo; internismo; representaciones visuales; proposiciones

\begin{abstract}
Since pictorial negation does not depend on internal elements, it can be conceived as an existential proof for logical externalism. This paper proposes to analyze pictorial negation in the context of reasoning by showing how external logical relations determine the content of images. I suggest for this a local externalism which narrows the analysis to specific reasoning contexts instead of the complete domain of logical relations. Far from rejecting Barceló's externalist alternative, my proposal aims to put his ideas to work.

Keywords: heterogeneous reasoning; externalism; internalism; visual representations; propositions
\end{abstract}

\section{Introducción}

El externismo es una concepción que se basa en la tesis de que "la estructura lógica y conceptual que revela el análisis no es interna al objeto de análisis, sino que incluye de manera esencial relaciones externas con entidades similares" (Barceló Aspeitia 2019, p. 9). En otras palabras, sostiene que todas las relaciones son externas, es decir, independientes de la composición interna de sus relata. Esta concepción se contrapone al internismo, según el cual "toda relación entre dos o más entidades es interna a ellas, es decir, depende de propiedades que cada una tiene independientemente de lo que sucede fuera de ella" (Barceló Aspeitia 2019, p. 153).

Diánoia, vol. 66, no. 87 (noviembre de 2021-abril de 2022): pp. 119-129 • ISSN: 1870-4913 DOI: http://doi.org/10.22201/iifs.18704913e.2021.87.1862 
El externismo surge como una solución prometedora frente a muchos problemas filosóficos. Aquí me centraré en el problema de la negación pictórica que presuntamente tienen las imágenes para expresar la negación de otras proposiciones (Bermúdez 2006; Bronner 2015; Rescorla 2009): por ejemplo, mientras que es posible representar pictóricamente que Biagioli está nadando, no se puede representar que Biagioli no está nadando. Cabe decir que la resolución de este problema tiene importancia para otros asuntos, tales como la naturaleza del contenido de las imágenes - ¿ies proposicional o no proposicional?(Grzankowski 2015), el razonamiento pictórico —ise puede razonar con imágenes? - (Barceló Aspeitia 2012), el pensamiento animal —ies posible pensar sin lenguaje?- (Morales Ladrón de Guevara 2011), el pensamiento conceptual - ¿son necesarios vehículos lingüísticos?(Heck 2007; Aguilera y Castellano 2020), etc. Más importante aún, la posibilidad de la negación pictórica constituye una prueba a favor del externismo porque, como veremos, la negación pictórica no depende de encontrar elementos internos en las imágenes que expresan la negación, lo que muestra que los operadores lógicos tampoco son esenciales para las relaciones lógicas.

En la siguiente sección presentaré en forma breve el problema de la negación pictórica. Luego de ponderar la solución que desarrolla Barceló, en la tercera sección presentaré mi propia propuesta que consiste en analizar la negación pictórica en contextos de razonamientos. En un sentido, mi propuesta puede verse como una forma de radicalizar el externismo de Barceló, pues muestra cómo el contenido de una imagen se determina por relaciones lógicas externas. En este sentido, propongo acotar el dominio de las relaciones lógicas externas (de todas las relaciones externas de una proposición) a contextos específicos de razonamiento. Igualmente, lejos de rechazar la variante externista de Barceló, espero poner a trabajar sus ideas.

\section{Representación pictórica y negación}

De acuerdo con Barceló, las representaciones pictóricas (visuales) se caracterizan por tener una relación de similitud visual entre la representación y lo representado. Según esto, los dibujos, pinturas, esculturas y películas son ejemplos de representaciones pictóricas.

El famoso Retrato de Enrique VIII de Holbein, por ejemplo, representa a Enrique VIII en parte porque reproduce cómo se veía dicho rey inglés. Igualmente, el cuadro de Rembrandt Palamedes ante Agamenón (1626) re- 
presenta la reunión entre Palamedes y Agamenón, no sólo porque lo dice en el título, sino también en parte porque podemos ver a ambos personajes en ella. (Barceló Aspeitia 2019, p. 180)

A partir de esta caracterización, hay quienes sostienen que las representaciones pictóricas no pueden representar la negación, pues ¿cómo ha de representarse algo que no se da, que no se ve o que no está? En otras palabras, no se puede establecer una relación de similitud si no está uno de los dos relata que constituyen dicha relación."Después de todo, sostienen, la negación de un hecho posible no se ve. Podemos ver lo que está sucediendo, pero no lo que no está sucediendo" (Barceló Aspeitia 2019, p. 181). Sin embargo, este argumento es débil porque es frecuente el uso de imágenes para representar seres mitológicos, mundos imaginarios y entidades (científicas) inobservables. Por otro lado, ya que no es lo mismo representar la negación (de que algo es el caso) que representar entidades inobservables o ficticias, el argumento no da en el núcleo del problema.

Un segundo argumento contra la negación pictórica descansa en la tesis de que el contenido de las representaciones visuales no puede ser general, sino sólo particular. Así pues, mientras que es posible representar pictóricamente que Javi está nadando o que Javi está parado fuera del agua, no se puede representar que Javi no está nadando (que es algo mucho más general que estar parado fuera del agua). En este caso, de la representación de Javi parado fuera del agua puede inferirse que Javi no está nadando debido a la incompatibilidad entre estar nadando y estar fuera del agua. Pero, a lo sumo, la incompatibilidad puede considerarse una variante débil de la negación. Más aún, habilitar la inferencia de la negación de $P$ no es lo mismo que representar la negación de $P$. Por lo tanto, concluye este argumento, no puede representarse pictóricamente la negación de que Javi está nadando.

Frente a este diagnóstico, Barceló propone que nos centremos en imágenes que no sólo son incompatibles, sino opuestas. En estos casos, sostiene, una imagen cuenta como la negación de la otra.

Una sombrilla está abierta si y sólo si no está cerrada y viceversa; por lo tanto, una sombrilla abierta es idéntica a una sombrilla no cerrada y viceversa. Un foco está encendido si y sólo si no está apagado, de tal manera que un foco apagado no es más que un foco no encendido, etc. (Barceló Aspeitia 2019, p. 183) 
Como cada uno de ellos es la negación del otro, podemos concluir que, por lo menos en estos casos, la negación pictórica es claramente posible. (Barceló Aspeitia 2019, p. 183)

En este sentido, Barceló sostiene que toda proposición representada pictóricamente es la negación de alguna otra: la imagen de un foco encendido representa la negación de que el foco está apagado y la de un paraguas abierto la negación de que el paraguas está cerrado. Sin embargo, esta alternativa no dejará conformes a los internistas, quienes exigen la presencia de un elemento negativo cuya formalización requiera algún operador de negación (Barceló Aspeitia 2019, p. 183). Por el contrario, el externismo rechaza que la negación requiera algún elemento u operador negativo, pues para este enfoque la negación es una relación externa, no una propiedad. Desde un punto de vista cognitivo, esto implica que se puede captar una proposición sin captar al mismo tiempo sus relaciones lógicas con otras proposiciones (Barceló Aspeitia 2019, p. 186).

Volvamos al segundo argumento. En primer lugar, este argumento es muy interesante, pues señala un aspecto característico de las representaciones pictóricas que resulta clave para comprender su papel inferencial. En particular, señala qué tipo de papel inferencial pueden desempeñar las imágenes, y no que no puedan desempeñar papel inferencial alguno. Si el contenido de las imágenes no es general, entonces podrán funcionar como premisas particulares (Aguilera y Castellano 2020). En segundo lugar, creo que tal vez debamos cambiar nuestras expectativas respecto a la respuesta a la pregunta de si podemos negar pictóricamente una proposición y dejar de esperar que haya una relación unívoca entre las representaciones oracionales y pictóricas (o entre las proposiciones y las imágenes). Puede ser que no haya una representación pictórica que represente de manera literal la negación de una proposición, sino muchas representaciones pictóricas compatibles con su negación. Además, esto no constituye un rasgo particular de la negación, sino una característica general de la relación entre las representaciones pictóricas y lingüísticas (Barceló Aspeitia 2012). Por ejemplo, podemos preguntar qué proposición expresa la figura 1. ¿Representa a Biagioli nadando, a Biagioli nadando en una pileta, a Biagioli nadando crol, a una mujer nadando crol en una pileta, el color del andarivel? ¿Cómo interpretamos esta incapacidad para elegir entre todas estas proposiciones alternativas? 


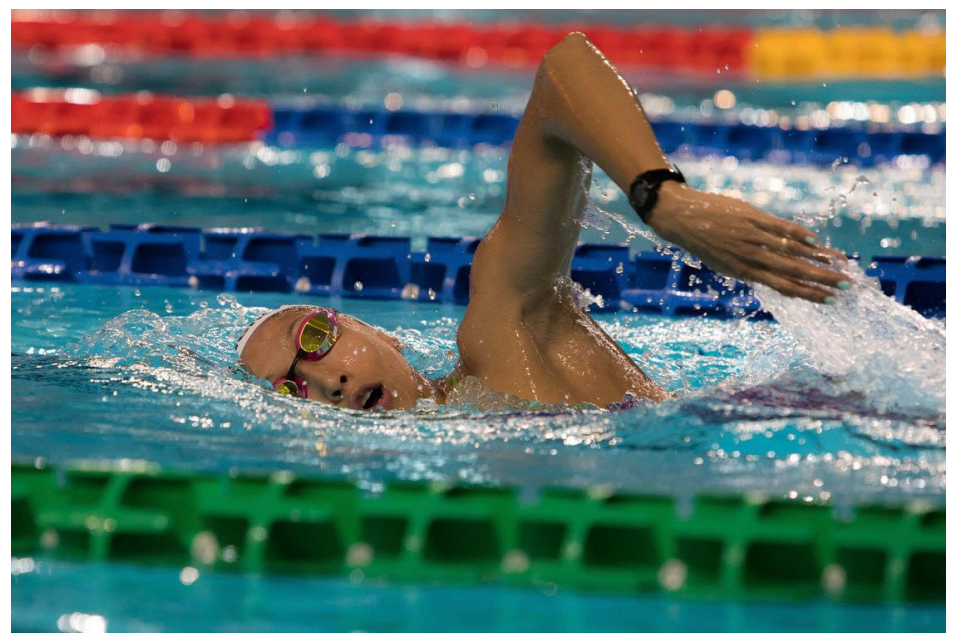

FIGURA 1.

Como veremos aquí, esta dificultad para decidir cuál oración entre todas las candidatas disponibles expresa el contenido de la imagen tiene consecuencias para la propuesta de la negación de Barceló. Se trata de una dificultad de la que sus ejemplos de imágenes opuestas no escapan. Si, como sostiene el autor, la negación pictórica se expresa mediante imágenes opuestas y se puede captar el contenido de una imagen sin captar al mismo tiempo sus relaciones lógicas con otras proposiciones —entre ellas, su negación-, entonces debería ser posible captar la imagen $I$ sin captar su negación. Ahora bien, ¿̇será posible captar la negación de $I$ sin captar al mismo tiempo I? ¿Cómo hemos de representar proposiciones contradictorias, por ejemplo $I$ y $J$ (donde $J$ equivale a $\sim I$ ), sin representarlas al mismo tiempo como relacionadas de alguna manera? Aun cuando la imagen de un paraguas abierto (I) sea opuesta a la imagen de un paraguas cerrado $(J)$, la imagen de un paraguas abierto expresa una proposición afirmativa que no evoca ni un paraguas cerrado ni su contradictoria.

Definir la negación pictórica en términos de pares de imágenes opuestas parece conducirnos a la conclusión de que no es posible, después de todo, expresar pictóricamente la negación de una proposición. Al parecer, la propuesta de las representaciones opuestas conduce al siguiente dilema: las imágenes sólo expresan proposiciones afirmativas o representan contenidos a secas; esto es, proposiciones irreductibles, hechos primitivos o algo por el estilo. Dado que Barceló sugiere que el 
externismo diluye la distinción entre las representaciones afirmativas y las negativas, lo único que queda es que las imágenes representen hechos primitivos o proposiciones no estructuradas, y esto debería generalizarse más allá de la negación a las otras relaciones lógicas. Y no sólo esto, sino que acarrearía un importante rasgo de las proposiciones y de las representaciones en general (incluidas las oraciones): si las imágenes representan hechos primitivos o proposiciones no estructuradas, entonces las oraciones también, y esto marcaría un rasgo central del externismo. Pero si esto es así, no parece que las representaciones pictóricas expresen proposiciones estructuradas, tal como Barceló Aspeitia 2019 (p. 196) sostiene.

Tal podría ser, quizá, el desenlace de un externismo como el que Barceló plantea, un externismo según el cual las proposiciones carecen de estructura. Sin embargo, pienso que podemos descartar esta interpretación. Si bien Barceló sostiene que las relaciones lógicas no son partes constitutivas de las proposiciones, ello no significa que éstas carezcan de estructura. Por el contrario, su tesis es que la estructura lógica de una proposición está determinada por sus relaciones lógicas externas (Barceló Aspeitia 2019, p. 155). A continuación propondré una forma de sortear este dilema que toma en cuenta el papel que pueden desempeñar las representaciones pictóricas en contextos inferenciales.

\section{Negación pictórica en contextos inferenciales}

En este apartado presentaré una forma de eludir el dilema anterior agregando algunos matices al externismo que defiende Barceló. Antes señalé que el problema de la caracterización de la negación pictórica que ofrece Barceló radica en que la negación de una proposición expresada por una representación pictórica involucra necesariamente su contradictoria. Sin contar con el par de contradictorias, no tiene caso hablar de proposición negativa o negación pictórica. Para resolver este inconveniente, propondré analizar la negación pictórica en contextos de razonamiento heterogéneos en los que se combinan premisas oracionales y premisas pictóricas (Aguilera 2021; Barwise y Etchemendy 1996). Como veremos, este análisis permite explicar tales dificultades como producto de ciertos rasgos clave de las representaciones pictóricas.

Veamos la siguiente imagen (figura 2). De acuerdo con Barceló, la figura 2 expresa la proposición "el paraguas está abierto". 


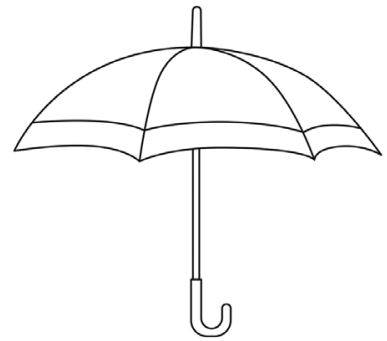

FIGURA 2. Barceló Aspeitia 2012, p. 183.

También sostiene que la figura 2 expresa la negación de la proposición "el paraguas está cerrado", su contradictoria, en virtud de la imagen opuesta (figura 3).

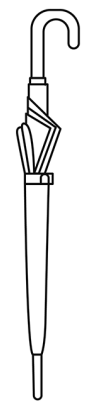

FIGURA 3. Barceló Aspeitia 2012, p. 183.

Sin embargo, también se podría decir que la figura 2 expresa la proposición "el paraguas está entero", para la cual tenemos la siguiente imagen opuesta (figura 4):

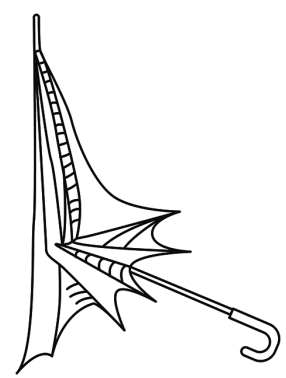

FIGURA 4. Imagen de un paraguas roto. 
De esta forma, la figura 4 expresaría la negación de la proposición que expresa 2 ("el paraguas está entero"). A su vez, 2 expresaría la negación de la proposición "el paraguas está roto". La pregunta es: ¿cómo elegimos, entre las distintas candidatas, cuál es la proposición que expresa 2 (Barceló Aspeitia 2012)? Se podría pensar que tal vez éste es un ejemplo problemático (en contra de la sospecha de Barceló), por lo que deberíamos buscar otro mejor. Sin embargo, es posible que refleje un rasgo central de las representaciones pictóricas. Como señalé también con respecto a la figura 1, no hay una relación unívoca entre las imágenes y las oraciones - el problema de la intraducibilidad- (Beck 2013) ni entre el contenido de las imágenes y las proposiciones - el problema de la subdeterminación-. Si este diagnóstico es correcto, ¿debemos rechazar la negación pictórica? ¿Debemos negar que las imágenes expresan proposiciones (Barceló Aspeitia 2019, p. 182, n. 14)? A continuación ofreceré una respuesta a la primera cuestión. Sin embargo, una respuesta a la segunda requiere un debate profundo, in extenso.

Detengámonos un poco en los siguientes ejemplos. Supongamos que Alfon quiere jugar con su paraguas y se pregunta si estará roto, pues vio a su perro jugando con él.

\section{Ejemplo 1}

El paraguas está roto o está entero

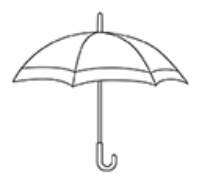

$\therefore$ El paraguas no está roto

\section{Ejemplo 2}

Si el paraguas no está entero, entonces está roto

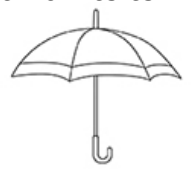

$\therefore$ El paraguas está entero

Alfon tiene inquietudes lógicas simples pero muy básicas. Así, prosigue:

Ejemplo 3

El paraguas está abierto o cerrado

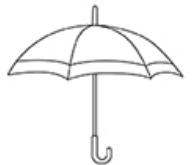

(EV)

\section{Ejemplo 4}

Si el paraguas no está abierto, entonces está cerrado

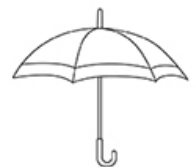

(MT)

$\therefore$ El paraguas está abierto

$\therefore$ El paraguas no está cerrado 
En el contexto de estos ejemplos es fácil determinar con mayor precisión cuál es el contenido que expresa la imagen. Veamos los ejemplos 1 y 3, que ilustran casos de una inferencia por exclusión. En estos casos podemos decir que la imagen del paraguas expresa tanto una proposición negativa como afirmativa: en el ejemplo 1, expresa la proposición "el paraguas está entero" que es idéntica a la negación de la proposición "el paraguas está roto". Que esto sea tan evidente para el caso de las imágenes explica por qué Barceló elige trabajar la negación pictórica como un punto a favor del externismo. No obstante, se podría objetar que la imagen de los ejemplos 1 y 3 expresa sólo un contenido afirmativo y que no sería un caso de negación pictórica.

Para responder a esta objeción, pasemos a los ejemplos 2 y 4 en los que figura la regla modus tollens. Así, en el ejemplo 2 la figura 2 expresa la negación de la proposición "el paraguas está roto". A su vez, en el ejemplo 4 la figura 2 niega que el paraguas esté cerrado. En este sentido, estos ejemplos de razonamientos permiten determinar con precisión cuál es el contenido de la imagen. Mientras que en el ejemplo 2 la figura 2 expresa que el paraguas está entero, de manera más precisa y con el fin de aplicar MT expresa el equivalente a la negación de su contradictoria, esto es, que "el paraguas no está roto"; en cambio, en el ejemplo 4 la figura 2 expresa que el paraguas está abierto o su equivalente, es decir, que el paraguas no está cerrado.

Como podemos ver con estos ejemplos, los contextos de razonamientos permiten especificar el contenido de una imagen; precisamente el contenido responsable de su contribución inferencial. Desde este punto de vista, en el ejemplo 2 podemos afirmar que la figura 2 niega que el paraguas esté roto. Aun así, el contenido de la figura 2 sirve para hacer una contribución diferente al razonamiento del ejemplo 4. En dicho contexto inferencial, la figura 2 expresa la negación de otra proposición, a saber, niega que el paraguas esté cerrado. En este sentido, la existencia de distintas proposiciones capaces de determinar el contenido de una imagen, esto es, la subdeterminación, explica por qué una misma imagen puede cumplir distintas funciones inferenciales en diferentes contextos argumentativos. Cabe destacar el papel que cumplen las oraciones (o las premisas oracionales) en los ejemplos 1-4 para señalar con precisión la contribución inferencial de las imágenes. Esto es, en virtud de la relación con las proposiciones que expresan tales oraciones es posible determinar el contenido de la imagen y, en particular, cuál proposición niega. 


\section{Observaciones finales}

Lejos de constituir una amenaza al externismo de Barceló, el análisis de los ejemplos presentados en cierta forma lo radicaliza. Dicho con mayor precisión, muestra cómo las relaciones lógicas externas en contextos inferenciales determinan el contenido de las proposiciones. Ofrece una manera de desambiguar o especificar el contenido de las imágenes, lo que permite dar cuenta en particular de la posibilidad de la negación pictórica. Por último, explota para su provecho la falta de correspondencia unívoca entre las imágenes y las oraciones y, por lo tanto, la subdeterminación del contenido proposicional de las imágenes. Lejos de obturar la negación pictórica, este rasgo clave de las imágenes permite explicar el gran potencial inferencial que tienen.

\section{REFERENCIAS BIBLIOGRÁFICAS}

Aguilera, Mariela, 2021, "Heterogeneous Inferences with Maps", Synthese, $<$ https://doi.org/10.1007/s11229-020-02957-w>.

Aguilera, Mariela y Federico Castellano, 2020, "Maps, Language, and the Conceptual-Non-conceptual Distinction", Grazer Philosophische Studien, vol. 98, no. 2, < https://doi.org/10.1163/18756735-00000119>.

Barceló Aspeitia, Axel Arturo, 2012, "Words and Images in Argumentation", Argumentation, vol. 26, no. 3, pp. 355-368, <https://doi.org/10.1007/ s10503-011-9259-y>.

Barceló Aspeitia, Axel Arturo, 2019, Sobre el análisis, Instituto de Investigaciones Filosóficas-unAM, Ciudad de México.

Barwise, Jon y John W. Etchemendy, 1996, "Heterogeneous Logic", en Gerard Allwein y Jon Barwise (comps.), Logical Reasoning with Diagrams, Oxford University Press, Oxford.

Beck, Jacob, 2013, "Why We Can't Say What Animals Think", Philosophical Psychology, vol. 26, no. 4, pp. 520-546, <https://doi.org/10.1080/09515089 $.2012 .670922>$.

Bermúdez, José Luis, 2006, "Animal Reasoning and Proto-Logic", en Susan Hurley y Matthew Nudds (comps.), Rational Animals?, Oxford University Press, Oxford, pp. 127-137.

Bronner, Ben, 2015, "Maps and Absent Symbols", Australasian Journal of Philosophy, vol. 93, no. 1, pp. 43-59.

Grzankowski, Alex, 2015, "Pictures Have Propositional Content", Review of Philosophy and Psychology, vol. 6, no. 1, pp. 151-163, <doi:10.1007/s13164014-0217-0>.

Heck, Richard G., 2007, "Are There Different Kinds of Content?", en Brian P. McLaughlin y Jonathan Cohen (comps.), Contemporary Debates in Philosophy of Mind, Blackwell, Oxford, pp. 117-138. 
Morales Ladrón de Guevara, Jorge, 2011, "Razonamiento animal: Negación y representaciones de ausencia", Revista Argentina de Ciencias del Comportamiento, vol. 3, no. 1, pp. 20-33.

Rescorla, Michael, 2009, "Predication and Cartographic Representation", Synthese, vol. 169, no. 1, pp. 75-200, <https://doi.org/10.1007/s11229-0089343-5>.

Recibido el 1 de febrero de 2021; aceptado el 15 de febrero de 2021. 